\title{
Exploring the Syntax of the Mo/Deg Adjective phrase
}

Anto, Sylvester Kwabena and Abraham Okrah

Department of Interdisciplinary Studies, College of Technology Education, University of Education, Winneba, Kumasi, Ashanti, Ghana, West Africa.

Abraham Okrah, Department of Education, Valley View University, Oyibi, Accra, Ghana, West Africa.

\section{ABSTRACT}

This study is largely syntactic and descriptive, and it explores the structure of the Mo/Deg adjective phrase. It, thus, provides answers to the question, "What is the nature of the Mo/Deg adjective phrase?" Data was gathered from thirty-five (35) literate native Mo/Deg speakers who were also very skilful in English language using purposive sampling as the ability to speak and write well in both English and Mo/Deg was crucial. Short simple English sentences which have the structure of the adjective were designed and given to the respondents to rewrite in Mo/Deg. This was done to observe the nature of the adjective structure in the language. Some of the sentences were also given to some staff of the Mo/Deg project of the Ghana Institute of Linguistics, Literacy and Bible Translation (GILLBT) to translate into Mo/Deg because they are ones considered to have deeper formal knowledge of the language. This was to make sure that the correct and acceptable order of the linguistic items in the adjective phrase in the Mo/Deg language was obtained. The translations comprised the data which were analysed using the Systemic Grammar concept of the adjectival group (phrase). The results showed that the Mo/Deg adjective phrase has place for the headword $(\mathrm{H})$ and the qualifier $(\mathrm{Q})$ but does not have a modifier $(\mathrm{M})$. It further found out that the qualifier function in the adjective phrase in the language may be realised by the adverb, the prepositional phrase, and the finite clause. The paper, thus, concluded that the adjective phrase in Mo/Deg language is quite a complex one though without a modifier.

\section{Indexing Iterms/Keywords}

Mo/Deg; adjective phrase; GILLBT; qualifier; modifier; Longoro; Dega; Degland,;Deg adjective

\section{ACADEMIC DISCIPLINE AND SUBDISCIPLINE Linguistics, syntax}

SUBJECT CLASSIFICATION: Language classification

TYPE (METHOD/APPROACH): Qualitative Research

\section{Council for Innovative Research}

Journal: Journal of Advances in Linguistics

Vol. 6, No. 1

editor@cirjal.com

www.cirjal.com, www.cirworld.com 


\subsection{INTRODUCTION}

Osei (2006: 4) and Naden (1988) intimate that the Mo/Deg language belongs to the Gur language family. It is spoken by over 30,000 people within the Brong-Ahafo and the Northern Regions of Ghana, Atta-Akosah (2004: 15 - 16). The two regions are divided by the Black Volta River which also separates the two major Mo/Dega towns, New-Longoro (Mantukwa) in Brong-Ahafo and Bamboi in Northern Region. The whole Mo/Degland was within the Ashanti Territory till the British colonial government carved out the Northern Territory in 1908, using the Black Volta river as the boundary without due consideration to the fact that one ethnic group had been divided over two territories.

The Mo/Deg language has two major dialects: Mangom and Longoro. The Mangom dialect is spoken in the south-south western part of the Northern Region of Ghana in places such as Bamboi, Jama, Jugboi, Nepui (Kapinta), Tasilima, and a few other places, while the Longoro dialect is spoken in the northern portion of the Brong-Ahafo Region in places like: Busuama, Kintampo, Old Longoro, Manchala, Fignyoa (Ahenakom), Kandige, Yaara, Tarbang, Soronuasi, Babatokuma, and other places. Within the Longoro dialect is another brand of the Mangom dialect different from the northern Mangom, and spoken in Mansie (Nyamboi). Yet another slightly different form of the Mo/Deg language which is between Mangom and Longoro is spoken in places like Adadiem, Dokachina and Bonakire in the Jaman North District of the Brong-Ahafo region. Furthermore, another dialect similar to the one spoken in the Jaman North District is spoken in Dwoboi, Wireke, and Zagala in L'Cote d'Ivoire.

Of the two major dialects, the Longoro dialect has been selected for this study because it is more indigenous.

The language is one of the minority languages in Ghana and little is known about it in terms of its grammar and syntax.

This study is syntactic in form and investigates the structure of the adjective phrase with the primary aim or reason of identifying the grammatical elements which constitute the structure of the Mo/Deg adjective, and in doing so, it interprets the meanings of the structures in English. However, it does not examine the functions of the adjective phrase in the language. It thus, answers the question, "What are the grammatical units which constitute the Mo/Deg adjective phrase?"

Very little literature or none at all exists on the structure of the adjective phrase and, so this work would be in no smal way very useful and important to linguists who want to have some firsthand literature on the Mo/Deg adjective. Also, it would be useful and important to the Ghana Institute of Linguistics, Literacy and Bible Translation (GILLBT) which is trying to document the grammar of the language.

\subsection{METHODOLOGY}

\subsection{Research Design}

Being qualitative in nature, the study employs the micro-ethnographic design technique of the ethnographic research design. This is because the micro-ethnographic design gives room for specific aspects of the culture of a people to be studied in details. Particularly, the micro-ethnographic technique has been applied because it allows detailed description, analysis, and interpretation of the Mo/Deg Adjective phrase to be made. Osuala (2001: 176 - 182) and Mustafa (2010: 52 ) are of the view that ethnographic study provides accurate and rich narratives and that the assertion of ethnographic study to high internal validity stems from the data collection and analysis techniques.

\subsection{Sampling and Population}

The purposive sampling selection technique was used to sample and select the population. This was to look for people who could read and write proficiently in both English and Mo/Deg. Consequently, thirty-five (35) participants were sampled and selected and, of this number; twenty (20) participants were selected from five traditional Mo/Dega towns namely: Busuama, Longoro, Mantukwa, Yaara, and Manchala, with four participants each coming from those towns. This was to make sure that a wide area of where native Mo/Deg is spoken was captured and also to have a variety of exact and acceptable presentations of the structure of the adjective phrase in the language. Additionally, fifteen (15) people were selected from among the staff of the Mo/Deg project of GILLBT to ensure further that more precise information was obtained. Short simple English sentences containing various structures of the adjective phrase were given to them to rewrite into Mo/Deg. The Mo/Deg versions of the English sentences were then used as data and analysed syntactically using the concept of Systemic Grammar framework.

\subsection{The Systemic Grammar Framework}

Systemic grammar was originated by M.A.K Halliday and his associates. Systemic grammar went through two important stages of development. Morley (1985) intimates that "the early form of the theory was known as scale-and-category grammar... which provides a framework for the analysis and description of any stretch of written or spoken language that has actually occurred."

The second stage of the development of systemic grammar started in the last half of the 1960s when Halliday's work was progressively more influenced by ideas on the functional nature of language and as a result assumed a semantic dimension. The theory at this time became known as systemic functional grammar.

The theory, according to Thakur (1998: 146) spells out three levels, four categories, and three scales of how language functions. The levels are form, substance and context, and the categories are unit, structure, class, and system, while the scales are rank, exponence, and delicacy. 


\subsection{Structure}

Structure, according to Morley (1984: 9), is the elements that are composed of a unit in terms of functional elements and the relationship that exists between the elements. Therefore, to say that a unit has structure is to say that it has a number of places which can be filled by the next smaller units, (Thakur, 1998:148). The structure of a group generally has a place for the modifier, the head, and the qualifier. Elements which precede the headword are modifiers and those which follow the head are qualifiers. The headword element is the most obligatory element on which all other elements syntactically depend and must therefore be filled or present in the group structure all the time. The modifier and the qualifier positions in the group structure exist at the level of potentials and may or may not be filled or realised. Thus, the structure of the group is represented as $(M)+H+(Q)$. This means that the elements in parentheses may or may not be filled while the $H$ element is obligatory.

This formulaic or schematic representation of the group structure applies to the adjectival group. For instance, the following adjectival groups are presented structurally as follows:

$$
\begin{aligned}
& \text { a. very glad indeed } \\
& \mathrm{m}+\mathrm{h}+\mathrm{q} \\
& \text { b. tall enough } \\
& \mathrm{h}+\mathrm{q} \\
& \text { c. so powerful } \\
& \mathrm{m}+\mathrm{h}
\end{aligned}
$$

\subsection{SYMBOLS AND ABBREVIATIONS USED}

For the purpose of this study, the following symbol(s) and abbreviations have been used.

$$
\begin{aligned}
& \text { ADJ = adjective } \\
& \text { ADV = adverb } \\
& \text { COMP = comparative particle } \\
& \text { DET = determiner } \\
& H=\text { headword } \\
& \text { INTV = intransitive verb } \\
& \text { 1PPL = first person plural } \\
& \text { 1PS = first person singular }
\end{aligned}
$$

2PPL/S = second person plural or singular

3PS $=$ third person singular

LNKV = linking verb

$M=$ modifier/modification

$\mathrm{NP}=$ noun phrase

$\mathrm{NEG}=$ negative

$\mathrm{PP}=$ prepositional phrase

PAST $=$ past form of the verb

$\mathrm{PRO}=$ pronoun

PROG = progressive

$Q=$ qualifier/qualification

REL PRO = relative pronoun

SUB = subordinator

TRANV = transitive verb

*unacceptable construction 


\subsection{THE STRUCTURE OF THE MO/DEG ADJECTIVE PHRASE}

The adjective is seen as a word "...used to describe or modify nouns or pronouns," Quagie (2009: $p$ 82). Taylor (2004: $p$ 191 ) and Annan (2000: p 26) see it as a word which specifies "...the attributes of nouns." In the Mo/Deg language the adjective describes the noun or specifies its (the noun's) attributes. For example:

$\begin{array}{ccc}\text { (i) } \text { Ton pag/paag } & \text { (ii) Papo lwee } & \text { (iii) Becha deege } \\ \text { Book ADJ } & \text { Leaf ADJ } & \text { Boy ADJ } \\ \text { Book large } & \text { leaf green } & \text { boy good } \\ \text { (large book) } & \text { (green leaf) } & \text { (good boy) }\end{array}$

The adjectives, pag/paag, Iwee, and deege describe or specify the attributes of the nouns respectively.

The structure of the adjective phrase according to Aarts and Aarts (1982: p 119) and Thakur (1998: $p$ 50) is made up of the head and the modifier. Aarts and Aarts are of the view that, "the function of the modifier may be realized by a constituent preceding the head." In the structure of the Mo/Deg adjective phrase we can distinguish only the head and the qualifier (post-modifier). That is, it has the structural pattern, $\mathrm{H}+\mathrm{Q}$. The Mo/Deg adjective phrase does not have any constituent preceding the head (modifier). However, a noun phrase or a nominal group may precede it with the adjective in a qualifier or post-head position so that the whole phrase becomes a noun phrase or nominal group instead. For example:
(i) Nen jang
(ii) Bonoo bang la
(iii) Kaah pong bel
Person ADJ
Boy ADJ the
Car ADJ a
Person tall
Boy big the
Car white a
(Tall person)
(The big boy)
(A white car)

All the adjectives: jang, bang, and pong are preceded by the nouns, Nen, Bonoo, and Kaah respectively, but, the phrases in which these adjectives occur are all noun phrases. Therefore, the nouns which precede them (the adjectives above) are not pre-modifiers of the respective adjectives.

\subsection{The Mo/Deg Adjective Head}

According to Annan (2000), the adjective head alone is the minimal form of the adjective phrase. The head is considered by Quirk, et al (1973: p 115) as a "...phrase with the adjective as head,...or as the sole realization..." The Mo/Deg adjective head consists of only the adjective. For example:
(i) som
(ii) pwere
(iii) swem
(iv) nyeg
(sweet)
(soft)
(red)
(sharp)

Greenbaum, et al (1990: p 127) says the adjective "...can take comparative and superlative forms. The comparison may be by means of inflections (-er and -est)... or by the addition of the premodifiers more and most." The Mo/Deg adjective does not inflect to show comparison, that is, it does not have comparative or superlative forms. Rather, comparison is shown by the use of the comparative particle, gwaa (more/than) which always follows the adjective in comparative constructions. Example:

$\begin{array}{cc}\text { (i) Som gwaa } & \text { (ii) Bori gwaa } \\ \text { Sweet COM P } & \text { short COM P } \\ \text { Sweet than } & \text { short than } \\ \text { (Sweeter than) } & \text { (shorter than) }\end{array}$

(iii) Kan gwaa

big COM P

big than

(bigger than)

Mo/Deg adjectives have two basic syntactic functions: postpositve and predicative. The postpositive adjectives include: kpeg (strong), jang (tall/long), kpel (bitter), togre (straight/right), lung (deep), bora (short), bingi (black), sale (useless/worthless), deege (good/useful), chooge (bad), bang (big), sweem (red), kol (blue), Iwee (fresh/green), holle (dry), pong (white), pag (large), etc. These adjectives usually follow the noun heads immediately in the noun phrase structure. For example:
(i) Bo lung la
(ii) Teg kpel
(iii) Nen choge
Hole ADJ DET
Hole deep the
(the deep hole)
Medicine ADJ
Person ADJ
medicine bitter
person bad
(bitter medicine)
(bad person)

The adjectives, lung, kpel, and chooge, follow the nouns, Boo, Teg, and Nen respectively in postpositive position. Where there is a post-head determiner as in (i), the adjective occurs right immediately after the noun but before the post-head determiner. Postpositive adjectives in the Mo/Deg language cannot be used predicatively except there is a change in their form. It is therefore not acceptable syntactically to have the following:

*Boo la lung or boo la do lung

*Nen la chooge or nen la e chooge 
The predicative adjectives occur only after the linking or copula verb BE which is either implicit/implied (absent) or explicit/overt (present). This is to say that any time the Mo/Deg adjective is used predicatively, the verb is, are, am, was, or were is absent or present. Those predicative adjectives which occur after implicit or implied verbs include: Kan (big/large), wer (good/nice/beautiful), too (white), bowhaa (lazy), sooh (smelly/concealed), som (sweet/tasty), etc. Below are some examples of how they are used:

(i) Dea no kan

House DET big/large

house this big/large

(This house is big/large)

(iii) Toli la bohwaa

Girls DET lazy

Girls the lazy

(The girls are lazy) (ii) Ton no too

\section{Book DET white}

Book this white

(This book is white)

The constructions above indicate that kan, too, and bohwaa are adjectives used predicatively. Although there is no overt or explicit use of the verb in all the constructions, it is understood by every speaker of the language that the verbs, is and are, are implied. What it means is that whenever the adjective is predicatively used in Mo/Deg as above, the $B E$ form of the verb is always implied. Syntactically, adjectives which occur after implicit or implied verbs may always appear after a mandatory post-head determiner, usually, la or no, as in (i) to (iii) above.

Other predicative adjectives which occur only after the overt/explicit verb BE include: jehng (quiet), kantang (tall and big/giant), timpong (fat/tubby), sakpaa (dirty/unhygienic), welewele (friendly), were (smart), pontom (sickly/unhealthy), gbolongton (fat/flabby/tubby), etc. Example:

\section{(i) Haah la do sakpaa. \\ Woman DET is ADJ \\ Woman the is dirty \\ (the woman is dirty)}

(ii) Ticha no do welewele.

Teacher DET is ADJ

teacher this is friendly

(this teacher is friendly) (iii) He do pontom.

2SP look ADJ

(You look sickly)

In the above constructions, sakpaa, welewele, and pontom are adjectives which occur after the verb, do, in each statement. The verb, do, is a linking verb in those constructions, and it is used overtly or explicitly. It is possible for some of these adjectives occurring after the overt or explicit verb, do, to be used postpositively. In such cases the adjectives are pronounced with high tones or if you like stress.

(i) Nen sakpaa (sakpaa pronounced with a high tone)

Person ADJ

Person dirty

(dirty person)

(ii) Tolo kpakee (kpakee pronounced with a high tone)

Girl ADJ

Girl skinny

(skinny girl)

It is allowable for some of the adjectives that occur after the implicit or implied verb BE to follow the overt or explicit BE. In such instances, the adjectives require the linking verb, do, (look/ to be) which may appear in imperative or persuasive constructions. Example:

(i) Ma dem la o do wer

IMPV house DET it LNKV nice

Build house the it look nice

(build the house to look nice) (ii) Te me o do kan

\section{IMPV me it LNKV big}

Give me it to be big

(give me a big one/make it big for me)

The adjectives, wer and kan, occur only after implicit or implied verbs. However, in the above constructions which are both imperative and persuasive in tone, they occur after the verb, do.

It is also possible for postpositive adjectives in Mo/Deg to be used predicatively; but such adjectives will need to take on inflectional morphemes. What it means is that postpositive adjectives can only be used predicatively if they change form. For instance, the adjectives in column A below are all postpositive while those in B are predicative as a result of adding inflectional morphemes to the postpositive ones. Column $\mathrm{C}$ gives the English interpretation or meaning of the adjective. 


\begin{tabular}{lcc}
\multicolumn{1}{c}{ A } & B & C \\
Jang & jangre & long/tall \\
Kpeg & kpegri & strong \\
Togre & togro & straight/upright/right \\
Lung & lungri & deep \\
Kpel & kpeli & bitter \\
Gbang & gbangre & fast/smart/quick \\
Bora & bori & short \\
pong & too & white \\
binge & biro & black \\
sale & salo & weak/useless \\
kol & kolo & ash \\
pang/paag & pangre/paagri & large \\
vol & vole & slippery
\end{tabular}

For example:

(i) Teega la kpeli

Medicine DET bitter

Medicine the bitter

(the medicine is bitter) (ii) Kaa no gbangre

car DET fast

car this fast

(this car is fast) (iii) Kere la kpegre

knife DET strong

knife the strong

(the knife is strong)

In the constructions above, kpeli, gbangre, and kpegre are predicative adjectives derived from the postpositve adjectives: kpel, gbang, and kpeg respectively. Kpeli, gbangre, and kpegre occur after the verb, BE, which is implied in those sentences.

Some adjectives such as deege (good/nice), som (sweet), sale (useless), etc, including the colour adjectives such as: binge (black), pong (white), sweem (red), kol (blue), etc, and the adjectives of shape and size like: bang (big/fat), pag/pang (large), bor (short), jang (tall/long), etc, show number contrast. That is, such adjectives in the Mo/Deg language have plural forms. Example:
(i) Yal sweem
(ii) Yal sweema
(iii) Da jang
(iv) Da janga
Cloth ADJ
cloth ADJ
Cloth red
cloth reds
(red cloth)
(red cloths)

\section{tree ADJ \\ tree tall}
(tall tree)

$$
\begin{aligned}
& \text { tree ADJ } \\
& \text { tree talls }
\end{aligned}
$$
(tall trees)

In (i) and (iii) the adjectives are sweem and jang which qualify the singular nouns Yal and Da respectively. In (ii) and (iv) the adjectives, sweema and janga are plural by the addition of the plural marker, a, although the nouns, $Y a l$ and $D a$, still remain singular. By their plural forms, therefore, the adjectives determine the number of the noun they qualify. Once plural adjectives co-occur with nouns, the said nouns must always be singular in form but they have plural connotations so as to agree with the plural adjectives. Usually, the form of the adjective tells whether the said noun is singular or plural. It is therefore syntactically and grammatically unacceptable to have a plural noun followed by a plural adjective in the Mo/Deg language. For instance, it is wrong to have the following construction:

$$
\text { (i) * Nera deega }
$$

People ADJ

People goods/nices

(good/nice people)

\section{(ii) * Bonoona janga}

\section{Boys ADJ}

boys talls

(tall boys)

These constructions are unacceptable in the language because in both (i) and (ii) deega and janga are plural adjectives, and by the syntax of the language they do not or, are not supposed to follow the plural nouns, Nera (people) and Bonoona (boys).

Many of the Mo/Deg adjectives are clausal in nature. That is, some Mo/Deg adjectives cannot be expressed as singleword adjectives as it is the case in English, but can only be expressed as clauses. For instance, the English adjectives: happy, glad, sad, responsible, capable, amiable, useful, fearless, ill, clever, important, truthful, wrong, and many others including what Wiredu (1998: p 55) calls the participles, (stolen, torn, beaten, crying, dancing, etc) can only be expressed as clauses. For example: 
(i) Nen o sie aa de le

Person REL PRO eyes INTV

Person whose eyes are being entertained

( happy person)

(ii) Nen waa de dawe wa

Person REL PRO is TRANV things

Person who is bothering about things

(responsible person)

It is observed that most adjectives which end in -ble or -ive can only be expressed as clauses.

\subsection{Qualification in the Adjective phrase}

Qualification (postmodification) in the adjective phrase is seen by Aarts and Aarts (1982: p 119) as a constituent 'following the head'. Greenbaum et al (1990: p 336) and Annan (2000: p 114) refers to it as the complement and explains it as:

$$
\begin{aligned}
& \text {...the grammatical patterns that follow....an adjective } \\
& \text { and complete the specification of meaning } \\
& \text { relationship which that word implies. }
\end{aligned}
$$

This implies that the qualification position of an adjective head is realised by a number a number of items which follow it.

The qualifier function in the Mo/Deg adjective structure is realized by any one of the following:

(i) adverb: tama, kohona, to, kerede, taen, peeh, and kpela.

(ii) the prepositional phrase, gwaa, operating as a comparative element, and

(iii) the finite clause.

\subsection{The Adverb as qualifiers}

The qualifier function in the Mo/Deg adjective phrase may be realized by the intensifier adverbs: tama, kohona, kerede, taen, peeh, to, and kpela. For example:
(i) Som kohona
(ii) pwere to
(iii) jugre tama
(iv) gbangre taen
Sweet ADV
Soft ADV
Tough ADV
Quick/fast/smart ADV
Sweet so
soft too
tough a bit
(a bit tough)
quick/fast/smart very
(very fast/smart/quick)
(so sweet)
(too soft)

The adjectives, som (sweet), pwere (soft). Jugre (tough) and gbangre (quick/fast/smart) are followed by the adverbs: kohona (so), to (too), tama (a bit), and taen (very) respectively in the adjective phrases above. The adjectives, pwere, jugre, and gbangre are predicatve only and occur only after implicit/implied verbs. Som is the only adjective which can be both postpositive and predicative. However, when it is postpositive, it has a low tone but, a high tone when it is predicative. Only the predicative adjective in the Mo/Deg language allows the intensifier adverb to follow it.

\subsection{The Prepositional Phrase, gwaa, as Qualifier Operating as a Comparative Element}

The morphology of the Mo/Deg adjective does not have any comparative form. However, to indicate comparison particularly by the use of adjectives, the prepositional phrase, gwaa, is used. It usually occurs after the adjective. The structure is usually, Adj + gwaa + an NG. Example:
(i) Too gwaa dombwe
White COMP NP
(ii) Nyegre gwaa fon
(iii) Gwegre gwaa konbelbwa
Sharp COMP NP
White than hailstone
sharp than razor blade
Weak COMP PRO
(whiter than hailstone)
(sharper than a razor blade)
weak than anything
(iv) On-swem gwaa chal
(v) On-nyeg gwaa fon no
(weaker than anything)

\section{Red COMP NP}
Red than blood

Sharp COMP razor blade DET
(vi) Kon-jug gwaa ono
sharp than razor blade this
Tough COMP PRO
(redder than blood)
(sharper than this razor blade)
tough than this
(tougher than this)

In (i) to (iii), gwaa, is used after the adjectives, Too, Nyegre, and Gwegre respectively to indicate comparison. Similarly, the adjectives, on-sweem, on-nyeg, and kon-jug in (v), (v), and (vi) respectively have, gwaa, following them. The 
adjectives in (i) - (iii) are predicative while those in (iv) - (vi) are postpositive. But sweem and nyeg have on prefixed while jug has kon prefixed. In fact, sweem and nyeg can equally be prefixed with kon and jug with on. What it means is that sweem, nyeg, and jug are postpositive, and where the postpositive adjective is followed by the comparative preposition, the said adjective will need to have either kon or on prefixed to it in order for it to make more sense.

\subsection{The Prepositional Phrases, te, ke, and ne as Qualifiers}

The prepositions, te, ke, and ne (all meaning for) with their usual nominal complements (in the case of te and ne) or adverbial complements (in the case of $k e$ ) seem to be the only prepositional phrases that can follow the Mo/Deg adjective. Example:

(i) Kan te ya sukuu

Big PP DET school

(Big for our school)

(iv) Jega ne dea doe

Small PP house build-PAST

Small for house built

(small for building a house) (ii) Wer te bwee no

Good PP town DET

Good for town this

(good for this town)

(v) Bori ne nen kee

Short PP person give-PROG

short for person giving

(short for a person as a gift) (iii) Jangre te ya bwa

Long PP 1PPL all

Long for we all

(long for us all)

(vi) Som ne dii

Sweet PP eat-PROG

(sweet for eating)

The examples above demonstrate the use of the adjective with prepositional phrases as the complements. The adjectives, kan, wer, and jangre in (i), (ii), and (iii) above have, te ya sukuu, te bwee no, and te ya bwa as complements respectively. In like manner, the adjectives: jega, bore, and som in (iv), (v), and (vi) have: ne dea doe, ne nen kee, and ne dii as complements. It is important to note that whereas ne has nominal clauses as complements, te has noun phrases. The syntax of the Mo/Deg language allows ne with a nominal clause only to complement the adjective. However, it is possible for te to be complemented by a nominal clause. For example:

(i) Wer te waa ya noa la

Good PP what 1PPL hear-PAST DET

Good for what we heard the (good for what we heard)

(ii) Kpegre te nera baa lo bono no

Strong PP people REL PRO are here DET

Strong for people who are here this

(strong for people who are here)

However, when the preposition ke follows the adjective, it allows only adverbial clauses to follow it. For example:

(i) Vole ke o vale o ta

Slippery PP 3PS walk 3PS on

Slippery for he walk it on

(slippery for him to walk on it) (ii) Sohne ke bii la di

Cold PP children DET eat cold for children the eat (cold for the children to eat)

(iii) Kohoo ke $n$ ba dem

Tired PP 1PS come home

Tired for I come home

(tired for me to come home)

The adjectives, vole, sohne, and kohoo are followed by the preposition, ke, which is also followed by clauses.

\subsection{The Finite Clause as a Qualifier}

One of the complements of the Mo/Deg adjective is the finite clause. The clause may be introduced by the subordinators: ke (that), nomanta (so/therefore), dekalke (because/since), and waa (because). For example:

(i) Wer ke ba nao

Good SUB 3PPL see-PAST-it

(good that they saw it) (ii) Biro nomanta maa $n$ sie na

Dark SUB NEG my eyes see

dark therefore not my eyes see

(dark therefore I cannot see ahead) 
(iii) Jangre waa ba yawo

Long SUB 3PPL buy-PST-it

(Long because they bought it, or

long that is why they bought it) (iv) Wilo dekalke he toole bono

Confused SUB 2PPL/S not there ADV

confused because you not there here

(confused because you were not here)

The constructions, (i) to (iv) have wer, biro, jangre, and wilo as adjectives which are followed by the clauses: ke ba nao, biro nomanta maa $n$ sie na, waa ba yawo, and dekalke he toole bono respectively. In (i), the postmodifier clause is introduced by ke, in (ii), nomanta, (iii) waa, and in (iv) dekalke.

In the syntax of the Mo/Deg language, the subordinators, waa and nomanta are mutually inclusive. That is to say that the two subordinators can co-occur within the same adjective phrase. For example:

(i) Gwegre nomanta waa baa looro topere belbwa

Weak SUB because 3PPL beat-PROG-him day DET

Weak so because they beating him day every

(weak that is they beat him every day)

(ii) Kpegri waa nomanta tolo la de nyino

Strong SUB so girl DET is love-PROG-him

Strong because so girl the is loving him

(strong so the girl loves him)

The above constructions show the co-occurrence of the subordinators, waa and nomanta within the adjective phrase structure. As illustrated in (i) and (ii) above, when the two subordinators co-occur, either of them can precede or follow the other without changing the intended meaning.

\subsection{CONCLUSION}

The paper has so far discussed the adjective phrase structure in the Mo/Deg language, and divulged that the adjective phrase is made up of the headword (adjective only) and the postmodification (qualification). The Mo/Deg adjective has no modification. It has plural forms and thus determines the number of the noun it qualifies. The Mo/Deg adjective has two syntactic functions: the predicative and the postpositive functions. The predicative adjectives are of two types: those adjectives which occur after implicit or implied verbs, examples of which include: kan, wer, som, jangre, bori, sale/salo, too, biro, kolo, sweero, sooh, bohwaa ,etc, and those which follow explicit or overt verbs, examples of which are: tempong, jein, kantang, sakpaa, pontom, narkpee, werewere, welewele, etc. The postpositive adjectives include: jang, gbang, bora, swem, bingi, kpel, chooge, etc. The study also revealed that for some postpositive adjectives to be predicative, they need to change form or take on some inflectional morphemes.

The study further revealed that the postmodification function in the adjective phrase structure may be realised by either the adverb, the prepositional phrase,gwaa, operating as a comparative element, the prepositional phrases, te, ke, and ne, and the finite clause.

\subsection{REFERENCES}

1. Aarts, F. and Aarts, J. 1982. English syntactic structures: Functions \& categories in sentence analysis. England: Pergamon Press Ltd.

2. Annan, J. C. 2000. English structure \& usage tody. Ghana: Krosana Book Foundation.

3. Atta-Akosah, T. 2004. Bible translation in christian mission: A case study of the spiritual and socio-cultural impact of the bible translation strategy of the GILLBT on the Dega people of Ghana. (Unpublished M.A. thesis). University of KwaZulu - Natal, South Africa.

4. Greenbaum, S., Quirk, R., Leech, G. \& Svartvik, J. 1990. A student's grammar of the English language. London: Longman.

5. Morley, G.D. 1985. An introduction to systemic grammar. London: Macmillan Publishers Ltd.

6. Mustafa, A. 2010. Research methodology. India: A. I. T. B. S. Publisher

7. Naden, T. 1988.'The Gur Languages'. In M. E. Kropp (ed). The Languages of Ghana. London: International African Institute.

8. Osei, K. J. 2006. A Report On Djga Project. (Unpublished). GILLBT. Ghana.

9. Osuala, E. C. 2001. Introduction to research methodology. $3^{\text {rd }}$ Ed. Nigeria: Africana-First Publishers PLC.

10. Quagie, J. K. 2009. English: A tool for communication. (2 ${ }^{\text {nd }}$ edn). Accra: Hybrid H Publication 
11. Quirk, R., Greenbaum, S., Leech, G. and Svartvik, J. 1973. A university grammar of English. India: Addison Wesley Longman.

12. Taylor, M. E. 2004. Modern English structure \& usage made simple. (2 ${ }^{\text {nd }}$ ed). Kumasi: Ash-Metro Prints.

13. Thakur, D. 1998. Syntax. New Delhi: Bharati Bhawan. 